\title{
DEVELOPMENT OF GEODATABASE FOR ARCHAEOLOGICAL SITE IN BUJANG VALLEY KEDAH
}

\author{
Nur Umaira Mohd Aminuddin, Zulkepli Majid, Nursyahira Ahmad Fuad, Anuar Aspuri, Mohd Faizi Mohd Salleh, Mohd \\ Farid Mohd Ariff, Khairulnizam M Idris, Norhadija Darwin \\ Geospatial Imaging and Information Research Group, Faculty of Built Environment and Surveying, Universiti Teknologi \\ Malaysia - numaira5@live.utm.my, nursyahiraaf@gmail.com, (zulkeplimajid, anuaraspuri, mohdfaizi, mfaridma, \\ khairulnizami, norhadija2)@utm.my
}

\author{
Commission VI, WG VI/4
}

KEYWORDS: archaeology, terrestrial laser scanning, geodatabase, point cloud, information system

\begin{abstract}
:
In recent years, there has been little adoption of geospatial technology applications towards the archaeological excavation project in Malaysia which yields increasing amount of data on historical assets. Those data however been processed and managed via conventional method of paper form- based and less associated spatial data which is actually can be necessary to improve the finding method of potential archaeological sites. This paper presents the application of Geographical Information System (GIS) towards the archaeology data management by adopting geodatabase for storing archaeology information and visualizing the archaeological monuments via method of 3D Terrestrial Laser Scanning (TLS). The research area is located within the Bujang Valley Archaeological Museum, Merbok, Kedah which known to locate most of the ancient relics that being preserved over time. The TLS method is used to scan the interior and exterior structures of the monuments due to its capability in representing 3D visualization digitally from point cloud data and close to the accuracy of the actual structure. In addition, the geodatabase can provide the organization a better medium to create large-scale databases for organizing, analyzing and sharing the products of the field research with other users. The GIS capability to capture, integrate, store, edit, analyze and display geospatial data can really help the effort in preserving the archaeological information from lost over time.
\end{abstract}

\section{INTRODUCTION}

Despite the civilization evolution through ages, it is important to perceive the fundamental knowledge of humanity and development of human manifestations to Earth. The archaeology, history and culture have strong linkage in contributing the national development [8]. Archaeology is commonly known as the research of past human behaviour through remaining materials to obtain cultural data from ancient times by applying specialised techniques. Then the obtained data become usable for those who interested in spatio-temporal variations of past human activities. Thus, it consists of both temporal and spatial elements as the procedures require observation, description and explanation of the way of human life [4]. The conservation and preservation programmes for the archaeological sites have been raised in Malaysia since 1990s particularly the archaeological cave sites [5].

Lately most of the archaeologists are looking forward to Geographical Information System or in well known term as GIS for providing time saving data acquisition techniques and to create large-scale databases for organizing, analyzing and sharing the products of their field research. The classification of GIS uses in which the first class is to record and map archaeological resources while the second class focuses on spatial analysis and the third use refers to publish the results of archaeological data by employing GIS interface. It can contain graphics, statistics, text and other elements to allow the selection of information for viewing and share information with interested agencies [10]. With the advent technology, terrestrial laser scanning (TLS) is widely applied in the documentation of archaeological features as the scanner proves high reliability and efficiency for regular archaeological work [7]. It is commonly adopted to acquire highly detailed terrain models and surface models of objects like building facades, statues and industrial. The technique attracts more attention as a reliable method in archaeological survey and documentation.

Generally TLS measurements are similar to total station as it allows to measure distances from objects, vertical and horizontal angles and the positions of the measured points with respect to the system's centre of origin. TLS is often combined with other acquisition methods such as photogrammetry to produce $3 \mathrm{D}$ digital visualisation from point cloud data processing [3]. 3D modelling can be powerful tool to understand, define and recognize the values of the site and the archaeological findings. The latest improvements in image based modelling algorithms and scanners allow utilizing a feasible, portable and affordable technique that can provide reliable and accurate both geometrical and morphological data eventhough the cost of 3D scanners is considered still high [1]. Add up with the application of GIS can potentially offers a better documentation of archaeology findings with geodatabase for easier data management and manipulation. The GIS capability to capture, integrate, store, edit, analyze and display geospatial data can really help the effort in preserving the archaeological information.

Numerous benefits can be obtained when using the geodatabase structure for storing large archaeological data as it can reduce the system files practice which is still mostly 
used by the current archaeologists in Malaysia. The advantages of geodatabase deal with the structure of GIS data and allow the creation of feature dataset which enables coordinated relationships between feature classes. Relationship classes are also important to connect fields in a feature class attribute table to another one fields feature class attribute table. This can prevent the repetitive data entry in multiple feature classes with less time cost [10]. The excavation process is carried out only either when the sites are threatened by destruction or when they can discover important information that cannot be found any other way [11]. Realizing of the threats has prompted them to record and document the heritage findings through conventional methods which are impractical as it is a time consuming process, ineffective presentation and require more manpower. Plus, no precise scale is applied for measurement purpose of documenting the archaeology findings [9].

The archaeological documentation tools have to fulfill the criteria of performance, accuracy, robustness, transportability, overall costs and careful handling of the products [6]. An example of research case in Bujang Valley shows that lots of shrines were found but none of them are digitally documented despite the use of filing system remains for the historical findings documentation [2]. The conventional method which remains applied in the archaeological data acquisition has constrained the efficiency of data management process to have geospatially-referenced integration. Therefore it often delayed the recording, storing and presentation of the archaeology findings due to the limited geospatial technology. This research aims to document the archaeological site using the method of 3D TLS and develop a geodatabase for archaeology information based on GIS. Several objectives are made in order to achieve this aim:

- To design and develop a geodatabase of the archaeology site

- To produce 3D visualization through modelling of the archaeological monuments.

\section{MATERIALS AND METHOD}

The overall methodology is divided into four phases comprising attribute data collection, field data collection, data processing and geodatabase design and development. In the first phase, the user requirement analysis and interview session are carried out to the stakeholder to acquire both primary data and secondary data that will be used for storing attribute data related to the archaeological findings. Since the research area has been determined, the base map of the research area can be created. In the next phase would be the data collection on the field of the research area which includes registration of GPS location and scanning monuments using TLS method. The raw product of point cloud data from the TLS then will be processed to produce the $3 \mathrm{D}$ visualization in the following phase. The last phase requires the research to design and develop the geodatabase for the archaeology site of Bujang Valley.

The three core database designs: conceptual design, logical design and physical design are created in the early of this phase before develop a geodatabase. Then, the 2D basemap of the research area can be integrated with the 3D model of the monuments which located at the site. The usage of the geodatabase will be tested and data stored in it can undergo simple analysis. Hence this section will discuss on the research area, sources of data, materials used and data processing involved throughout the research. The general process for the development of geodatabase for archaeological site in Bujang Valley is shown in Figure 1.

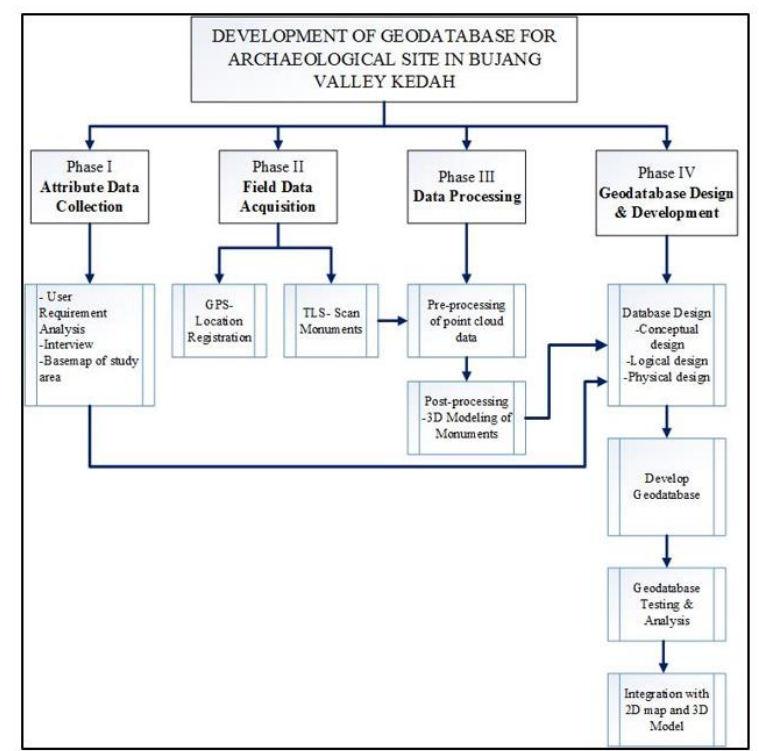

Figure 1: The flowchart of the Development of Geodatabase for Archaeological Site in Bujang Valley, Kedah

\subsection{Description of Research Area}

Bujang Valley has been known as one of the most historic discoveries in Malaysia as over hundreds of archaeological findings including artifacts and monuments are found within the area itself. It is believed that an ancient Hindu-Buddhist kingdom has ruled the place as early as $300 \mathrm{AD}$ as indicated by an archaeological research [2]. Bujang Valley is located in Mukim Merbok, south Kedah with area coverage of $224 \mathrm{~km}^{2}$ and positioning between latitude $5^{\circ} 44^{\prime} \mathrm{N}$ and longitude $100^{\circ}$ $24^{\prime}$ E. It is near to the Kedah's highest peak with high 1300 meter namely Gunung Jerai which was the most visible landmark for sea traders heading to the region. The rivers that flow through the mount are Sungai Muda and Sungai Merbok. From a geographical single valley have three main units of mountains, barren hills and valleys also river beaches. Since many of the physical monuments exist subsurface,

The Department of National Heritage Malaysia is the responsible body who manages the excavation, relocation and rehabilitation of shrines and relics found in the area and some area is worked out by the Centre of Global Archaeological Research, Universiti Sains Malaysia. Specifically, the archaeological site for this research is within the area of Bujang Valley Archaeological Museum. By which, the relics of the Hindu-Buddhist kingdom are displayed at here including monuments, stone caskets and tablets, metal tools and ornaments, ceramics, pottery and Hindu icons [2]. Given the existence of a number of written records, including those from Chinese and Arabian seafarers and also literature from India, the importance of the Bujang Valley sites in development of old Kedah is well-established. So far, the museum keeps only four monuments within the museum area namely Site 8, Site 16, Site 21 and Site 50. The location of Bujang Valley as the research area is shown in Figure 2. 


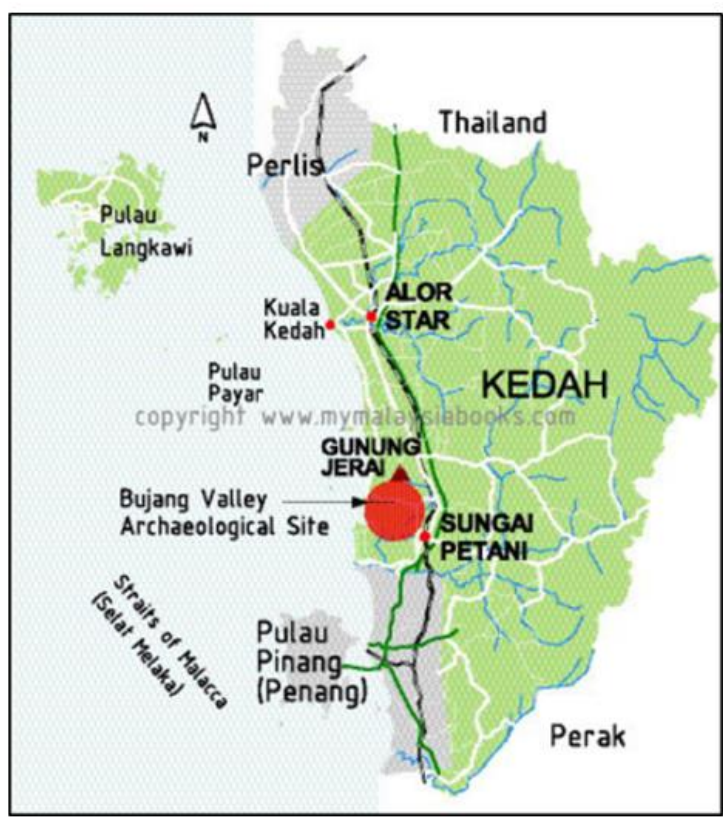

Figure 2: Map of Kedah and the location of the Bujang Valley Archaeological Site [12]

\subsection{Data Collection}

Data collection phase is the initial phase to conduct a project with a purpose for obtaining data and information required based on the research interest. It includes commonly from primary data and secondary data in which in this project, the process of data collection is distinguished by types of data of attribute and spatial components that are discussed in Phase I and Phase II respectively.

\subsubsection{Phase I: Attribute Data Collection}

Since attribute data plays vital part in creating a geodatabase, the need assessment is carried out carefully. Here, the secondary data incorporates existing attribute data about the archaeology site description and details of monuments. These data are acquired from various sources as the Bujang Valley Archaeological Museum, article papers, reports and books. An interview session is conducted towards the curator assistant and an archaeologist worked in the museum in order to collect related information about the monuments placed at the site. Because the museum used conventional method to store the entire attribute data, all the data is printed in form of hardcopy but not all the data can be obtained directly.

The data collection is also supported with a report book on the excavation of one of the monuments (Site 8 ) provided by the archaeologist and a book titled Tamadun Awal Lembah Bujang as shown in Figure 3. Plus, more details are also required from an article about the monuments of the Bujang Valley. Those collected data includes the location and excavation of the monuments found in the valley, the description of each sites, the dimension and materials of the structure, the founder of the site, the reliquaries and their contents and more about the archaeological site. Additionally, a base map required in this research which used to map the distribution of the monuments is downloaded from the Open Street Map and DIVA-GIS website in vector format. The base map is then georeferenced using five points of field data in ArcMap.

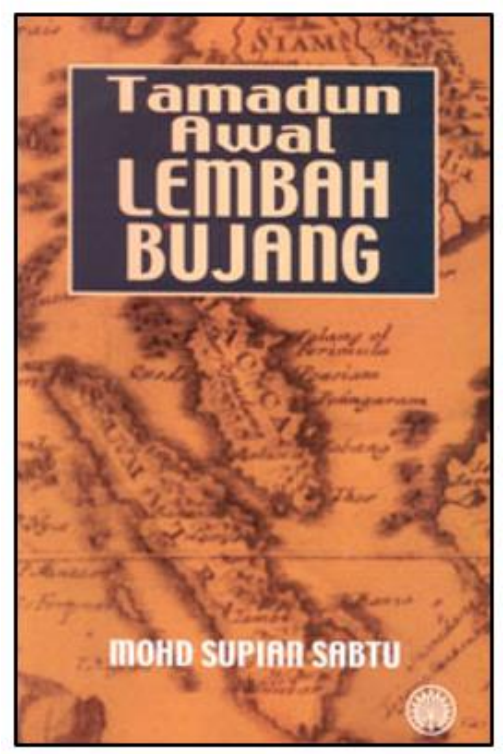

Figure 3: Book of Tamadun Awal Lembah Bujang

\subsubsection{Phase II: Field Data Acquisition}

The spatial data collection takes place the most in this phase in order to survey the Bujang Valley archaeological site. The process of field data acquisition is executed using the Global Positioning System (GPS) and Terrestrial Laser Scanning (TLS) instruments. The location registration of the site is conducted via GPS to collect adequate coordinates for georeferencing on the basemap in order to locate actual location of the monuments. Because the monument has complex feature and rough surface for its inner and outer shape hence laser scanning method by TLS is utilized to capture the geometry and intensity of the façade data.

\subsubsection{Locating Site and Monument via GPS}

The GPS instrument is used as an essential tool to establish the coordinates of each monument over the research area. The GPS survey utilized a handheld GPS receiver of Garmin Montana 610 with accuracy from millimeters to 10 meters. The coordinates for each monument are registered in World Geodetic System 1984 (WGS84) as the reference coordinates system and in Latitude and Longitude unit. The GPS data then is transferred relatively to GPS processing software, GPS Pathfinder Office to export the coordinate dataset that has been recorded during the field data collection.

\subsubsection{3D Laser Scanning}

The scan of the interior and exterior monuments in the archaeological site is performed by laser scanning method of TLS with a compact high speed 3D laser scanner Topcon GLS-2000. It provides a $360^{\circ}$ for horizontal direction and $270^{\circ}$ for vertical direction field of view, a long range scanning up to $350 \mathrm{~m}$ and has scan rate upto 120,000 points per second. The system also capable to emit faster pulse signals which produce a clear signal waveform enabling timing to be detected more precisely in signal processing. The product comes with capability of single point accuracy with $3.5 \mathrm{~mm}$ at 1 to 150 meter range.

The positions of the scanner are carefully planned to capture full coverage of each monument's details with good resolution and accuracy. The field work is executed by using 
tie-point registration method. This method is effective for accurate and secure merging of multiple scanned data. The numbers of total scan station rely on the size and complexity of the monument structure. For this project, only three out of the four monuments (Site 8, Site 16 and Site 50) are being scanned by TLS. Only Site 21 is not scanned because of the monument is enclosed by fences and roof which make it difficult to establish scan stations.

The distributions of control points are fairly located at a distance around 1.5 meters to 4 meters from the scanner in order to obtain a good geometry network. The control points are needed to set in a position that could be seen and corresponded between two scan stations which require minimum 3 corresponding target. The control points used are the ones with black and white target mark and prisms. For all of the three monuments, it takes around five to ten scans are acquired with medium scanning resolution. The procedure of the data scanning is shown in Figure 4.

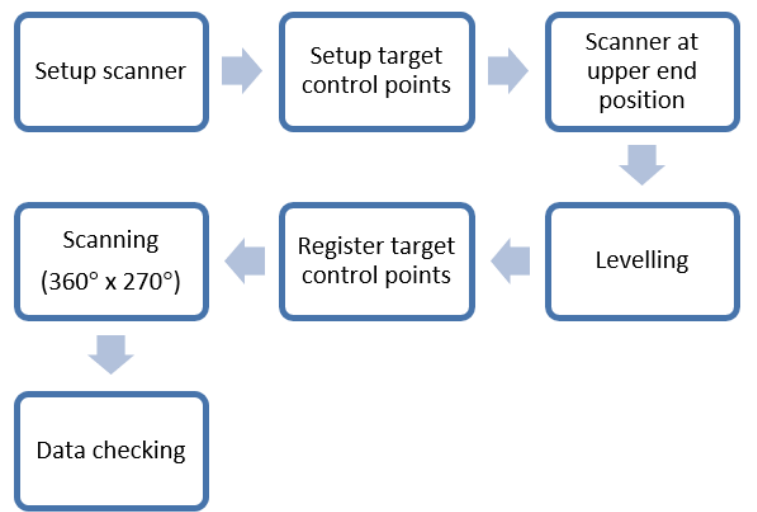

Figure 4: The procedure of data scanning

\subsection{Phase III: Data Processing}

This phase takes first step of pre-processing the point cloud data and last step of post processing of 3D modelling generation. In the pre-processing, Magnet Collage software is used for raw point cloud data processing which involves importing data, the data filtering and registration whereby the resulting scanned data is saved in las format. The registration of the scanned point data involves the matching of control point in one common coordinate system in which it is performed pair by pair by means of minimum 3 control points in order to match two different datasets.

Since millions of detail measurements are taken, it may contain several noise and errors therefore data filtering process are doing to remove unwanted point cloud. Figure 5 shows the procedure for pre-processing of point cloud data. Whilst the post-processing requires the production of $3 \mathrm{D}$ modelling of monuments based on the registered point clouds. Here, different software is used namely Quick Terrain Modeller for producing a mesh 3D model from the las format data for each of the monuments. The 3D model then is exported to GEOTIFF DEM. Figure 6 shows the registered and edited point cloud data of Site 8 in $3 \mathrm{D}$ view.

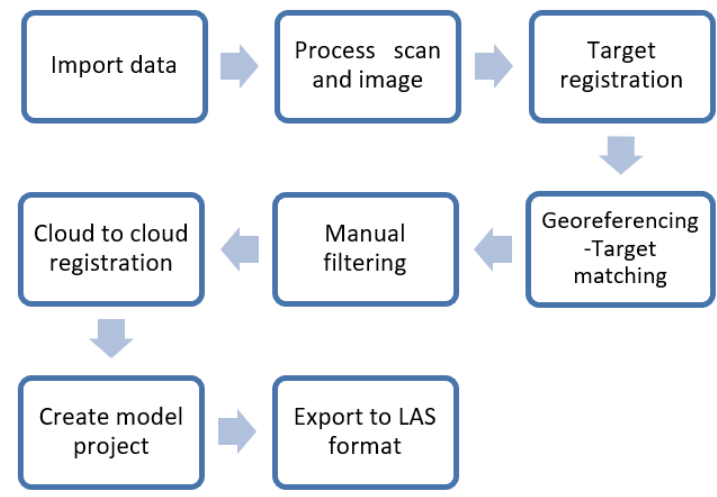

Figure 5: The procedure of pre-processing point cloud data

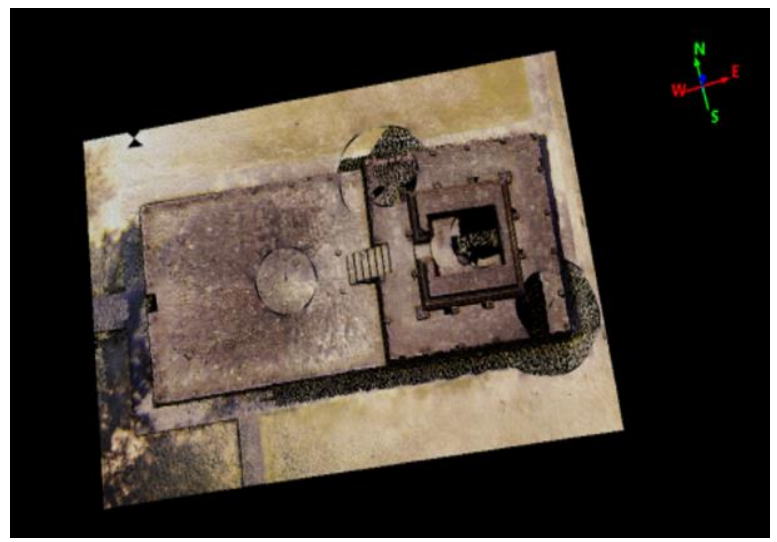

Figure 6: The 3D view of point cloud data for Site 8

\subsection{Phase IV: Geodatabase Design and Development}

\subsubsection{User Requirement Analysis}

The need assessment is planned as essential part in understanding the user requirement towards the development of the geodatabase. This is to improve the weakness of the conventional method used to store the archaeological data while offering better method of data storage. Therefore an User Requirement Analysis (URA) is conducted to firstly identify the requirements of the user in detail and gather potential data that will be much used as input of the geodatabase. Interview sessions are held towards the representatives of Bujang Valley Archaeological Museum who is the Curator Assistant and former archaeologist. A set of questionnaire is made to investigate what types of available data as well as how the archaeological records are managed and stored.

After the results from URA is obtained, the results are evaluated. The question are answered by the staffs regarding the following information:

- $\quad$ Aim and objectives of museum

- Existing data and information

- The needs of GIS in the archaeological data management

Besides the following information, the hardware and software used by the museum are also identified. 


\subsubsection{Database Design}

Geodatabase allows the determination the relationship between related spatial data and non-spatial data. The structural elements for a geodatabase are domains, relationship class and geometric network. Hence, a database design must include a detailed structure of a database therefore it is important draw out the three important components in it which are conceptual design, logical design and physical design. The conceptual design plays important role to illustrate all the data contain in the database, the structure of the data and its behavioural properties. The conceptual model can be represented through EntityRelationship diagram.

The ER diagram gives a graphical overview of the database by determining the entity, attribute and relationship for each data. This is to meet the understanding between the users and developers on things that required for the application. Figure 7 shows the ER diagram for this research. Based on the figure, the diagram consists of the spatial and non-spatial entities, their attributes and connected relationship exist between them are determined. Spatial ER diagram is used to differentiate the entities according to spatial and non-spatial. The ones with the geometry symbol (polygon, line, point) on top left of the entity denote the spatial data. The Monument and Archaeology Site are the main entities for the geodatabase as other entities are mostly connected to them.

Meanwhile the relationship that can be exampled in this research can be portrayed as; each archaeology site has one or more monuments while each monument has records on excavation and registration tables. This diagram is designed in detail as it represents the key to the development of the geodatabase. The logical database design defines the relation schemas in which the primary keys and foreign keys are established in the ER diagram. The goal of the last phase in the database design is the physical design that is meant to implement the database. The ER diagram is then translated into a working model in ArcCatalog soon after the database designs are completed.

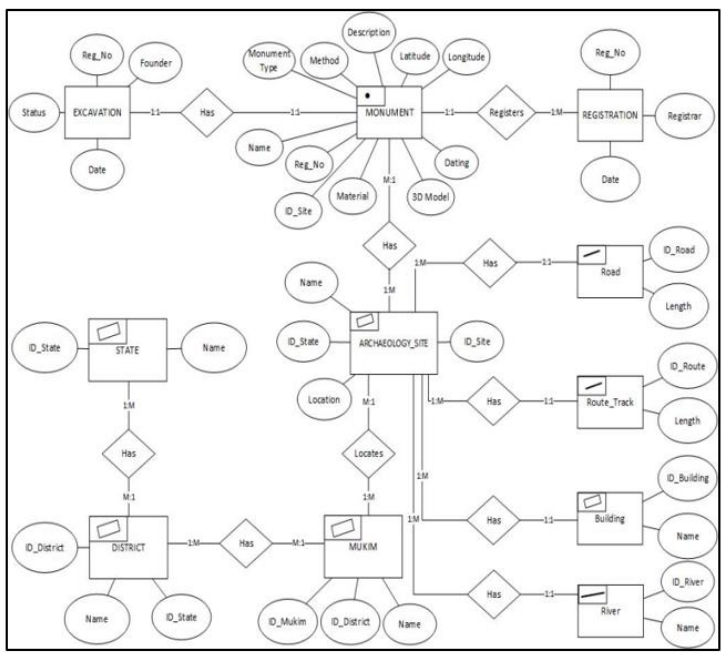

Figure 7: Entity Related Diagram

\section{RESULTS AND DISCUSSION}

After the database designing process takes place, the data is added in the database. This involves creating the geodatabase manually using ArcCatalog. Hence, a file geodatabase named
Lembah Bujang is created as shown in Figure 8. The process also includes defining its dimensions, creating individual feature datasets and feature classes, domains and assigning attribute fields within each feature class. The geodatabase consists of spatial and attributes data which have been acquired from the basemap, the books, reports and articles previously during the attribute data collection. Meanwhile, the concept of 'whole to the part' is applied when making the basemap for the geodatabase. This is to locate the distribution of the monuments found within the particular area besides the research area. Moreover, the representation of the two dimensional map of the archaeological site can be displayed in the ArcMap which also provides a great database management tool for editing the spatial content.

\begin{tabular}{|c|}
\hline 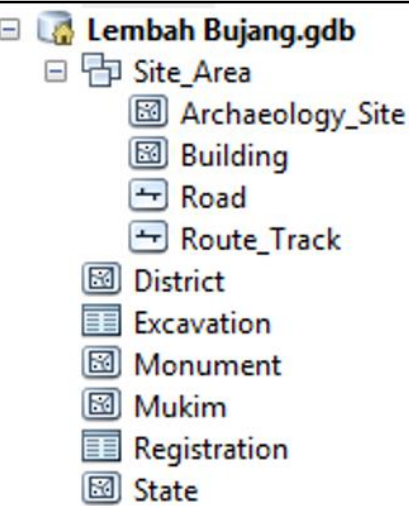 \\
\hline
\end{tabular}

Figure 8: File geodatabase in ArcCatalog

Despite of the conventional method which using filing system practiced by the users, this geodatabase also allows the data entry and query process in order for retrieve, edit and updating data. In order to test the effectiveness and thoroughness of the geodatabase, several queries are made by using the function Using the Select by Attribute feature in ArcMap records. Figure 9 shows the result of the query process in the geodatabase. ArcGIS software supports various of data types, the geodatabase also capable to support the entry of $3 \mathrm{D}$ files used to store the $3 \mathrm{D}$ models of the monuments. One or more 3D files can be imported into a multipatch feature class while preserve the texture of 3D models by storing the output multipatch in the geodatabase. The input 3D model file can be in either 3D Studio (*.3ds), OpenFlight (*.flt), VRML (*.wrl), or SketchUp format (*.skp). Note that these formats can be stored in ArcGIS geodatabase are for 3D model drawings only.

Another method to implement the integration of 3D models into the geodatabase is by using field-based hyperlink tool that can be created in the field of Monuments feature class. The hyperlink is set for each point of monuments in the research area and when the hyperlink button is used to click on the point feature, it will automatically bring up the hyperlink information to the file of 3D model. Since the 3D models are stored as QT Modeller Surface Model format, it will prompt the software to open the 3D model file. Therefore the integration of the archaeological site map from the basemap and 3D visualization as shown in Figure 10 can be executed which potentially seems to make the geodatabase more interesting to the user. 


\section{CONCLUSION}

The implementation of GIS can potentially offer a better documentation of archaeology findings with better tool towards easier data management and manipulation. Throughout this research, the aim of to document the archaeological monuments using the method of 3D TLS and the development of geodatabase for archaeology information are achieved. The final outputs of geodatabase and 3D visualization developed for Bujang Valley Archaeological Museum can also be used to other organizations that wish to preserve the valuable archaeological assets while getting more discoveries. Numerous benefits can be obtained when using the geodatabase structure for storing large archaeological data as it can reduce the system files practiced by the users.

The TLS method also allows the scanning of archaeological monuments in a digital environment makes ease of data sharing and transaction besides able to support further visual analysis on the data efficiently. This effort will also enhance the productivity of the site data acquisition during the excavation process and the product of the $3 \mathrm{D}$ representation can inspire more applications and research in the archaeology field while integrating with GIS as part of the powerful tool.

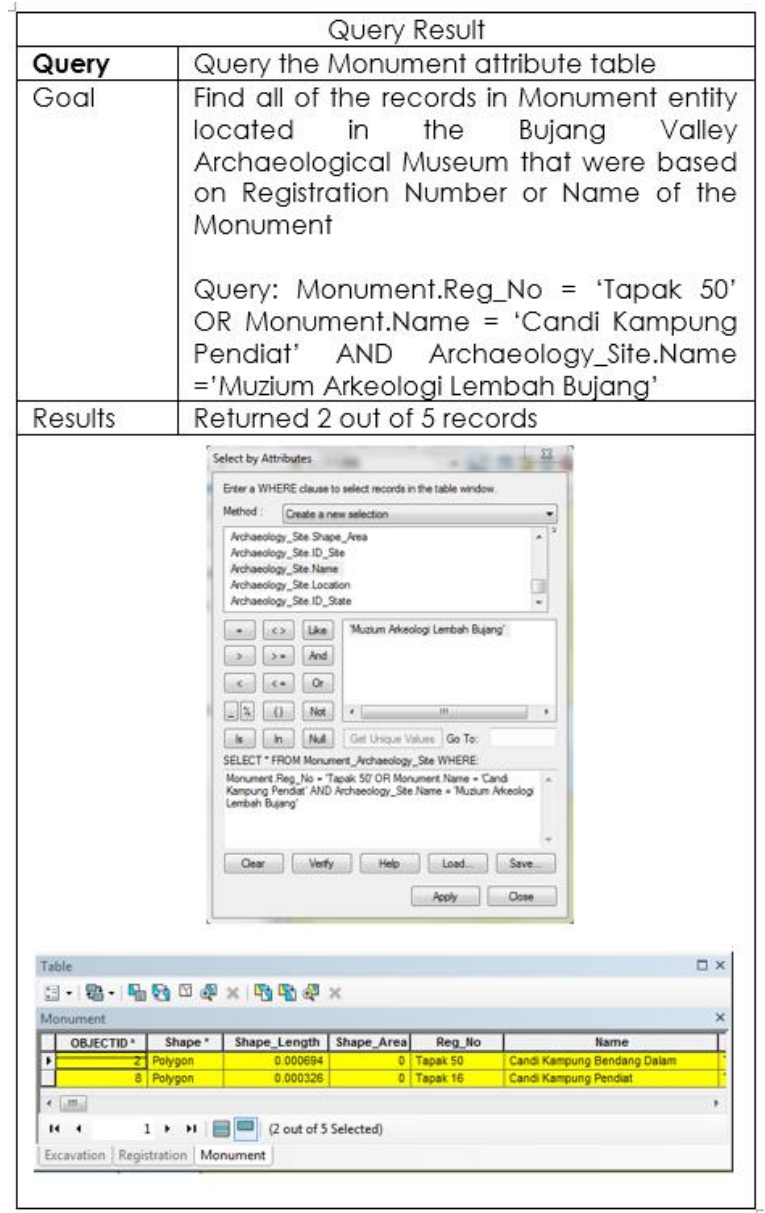

Figure 9: Result of the query process in geodatabase

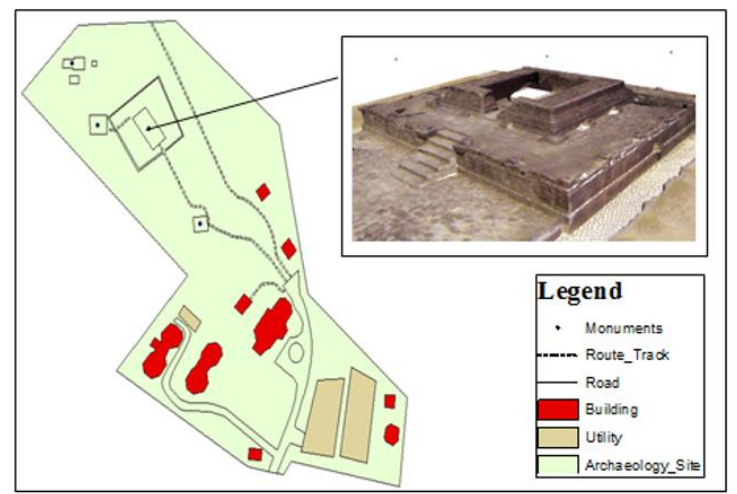

Figure 10: The base map of Bujang Valley archaeological site and 3D model of monument

\section{Acknowledgement}

The authors would like to thanks to the representatives of Bujang Valley Archaeological Museum and Department of National Heritage for their assistant in gathering the related information. This research is part of the Universiti Teknologi Malaysia Research Grant under the vot number 05G12.

\section{References}

[1] Abate, D., Avgousti, A., Faka, M., Hermon, S., Bakirtzis, N., Christofi, P. (2017). An Online 3D Database System for Endangered Architectural and Archaeological Heritage in the South-Eastern Mediterranean. The International Archives of the Photogrammetry, Remote Sensing and Spatial Information Sciences, Volume XLII-2/W3

[2] Bachad, E. W., Majid, Z., Setan, H. (2013). GIS Application and Geodatabase for Archaeological Site Documentation System: Bujang Valley, Malaysia. Developments in Multidimensional Spatial Data Models, pp. 173- 189.

[3] Baxter, C.L., Jankiewicz, S.E., Calfas, G.W. (2017). Terrestrial Laser Scanning in Archaeology and Cultural Heritage Management. Retrieved from https://www.rdmag.com/article/2017/08/terrestrial-laserscanning-archaeology-and-cultural-heritage-management

[4] Geospatial World. (2010). GIS Application in Archaeology.Retrieved from https://www.geospatialworld.net/article/gis-application-inarchaeology/

[5] Goh, H. (2014) 'Cave Archaeology of the Lenggong Valley, Malaysia: A Heritage Management Perspective', (August). Available at: http://flex.flinders.edu.au/file/906cf24c-731d-47bf9aa7f21c198116f4/1/Thesis-Goh-2014-Abstract.pdf

[6] H. Mara - R. Sablatnig. (2005). 3D-Vision Applied in Archaeology. Forum Archaeologiae 34/III/2005. Retrieved from http://farch.net.

[7] Neubauer, W. (2007). Laser Scanning and Archaeology, Standard Tool for 3D Documentation of Excavations. Retrieved from https://www.giminternational.com/content/article/laserscanning-and-archaeology 
[8] Ramli, Z. (2014). Archaeology, Culture and History: Concept and Their Contribution in Malaysia. 7thInternational Seminar on Ecology,Human Habitatand Environmental Change in the Malayworld.pp.28-38

[9] Sulaiman, N. S., Majid, Z. and Setan, H. (2011) 'Innovation in Archaeological Documentation Methods - a Review', (June), pp. 22-24.

[10] Tennant, E. G. (2009). Using Geodatabases to Generate "Living Documents" for Archaeology: a Case study from the Otago Goldfields, New Zealand. Historical Archaeology, Vol. 43, No. 3, Current study in Australia and New Zealand, pp.20-37

[11] Voices of the Sandhills. (2010). Archaeology, How do Archaeologists Excavate Sites? Retrieved from http://www.voicesofthesandhills.com/archaeology/excavate. $\underline{\mathrm{html}}$

[12] Kalyanaraman, S. (2011). Kidaram kondan and Bujang Valley, Kedah: Indian Ocean Community. Retrieved from http://bharatkalyan97.blogspot.my/2011/07/jayankondam. 